\title{
Species polyphyly and mtDNA introgression among three Serrasalmus sister-species
}

\author{
Nicolas Hubert ${ }^{\mathrm{a}, \mathrm{b}, \mathrm{c},{ }^{*} \text {, Juan Pablo Torrico }}{ }^{\mathrm{b}, \mathrm{c}}$, François Bonhomme ${ }^{\mathrm{c}}$ and Jean-François \\ Renno ${ }^{\mathrm{a}}$, b, c
}

\author{
aU.R. 175 Institut de Recherche pour le Développement (IRD), GAMET, BP 5095, 361 rue JF Breton, 34196 \\ Montpellier Cedex 05, France \\ ${ }^{b}$ Instituto de Biologìa Molecular y Biotecnologìa, Universidad Mayor de San Andres, La Paz, Bolivia \\ 'Laboratoire Génome, Populations, Interactions, Adaptation, CNRS-IFREMER-Université Montpellier II, UMR \\ 5171, SMEL, 1 quai de la daurade, 34200 Sète, France \\ *: Corresponding author : N. Hubert, email address : myloplus@excite.com
}

Keywords: Characidae; Neotropics; Introgression; Ancient polymorphism; mtDNA

\section{Introduction}

Understanding the processes that generated pattern of DNA variation in natural populations may be a difficult task. Since migration and gene flow may superimpose to genetic drift and divergence, evolutionary forces responsible of shared polymorphism may be difficult to identify (Pamilo, 1988; Nielsen \& Wakely, 2001). In this context, the raise of the coalescent theory constituted a significant improvement in the comprehension of the theoretical framework behind gene genealogies (Kingman, 1982; Tajima, 1983) and its application to the analysis of DNA sequences has proven to constitute an informative approach to the problem of shared polymorphism (Chiang, 2000; Takahashi et al., 2001; Machado \& Hey, 2002; Rokas et al., 2003; Bowie et al., 2005). The coalescent theory predicts that haplotype sharing will persist at the incipient stage of species divergence between species that founded from the same gene pool (Rosenberg, 2003). This stage of shared polymorphism without gene flow has been previously formalised as the lineage sorting period (Hoelzer et al., 1998). This step is characterised by the occurrence of coalescent events between alleles from isolated groups leading to erratic genealogies (Pamilo, 1988; Funk, 2003). However, recently diverging groups may still exchange genes and distinguishing between gene flow and ancestral polymorphism may be a difficult task (e.g. Nielsen \& Wakeley, 2001). The piranha belongs to the characidae subfamily of Serrasalminae (Buckup 1998). Currently including 28 species ranging from $130-420 \mathrm{~mm}$ standard length, the piranha genera Serrasalmus and Pygocentrus constitute the most speciose group of large carnivorous Characiformes (Jégu 2003). DNA sequences from mitochondrial DNA (mtDNA) recently evidenced that these genera constitute a monophyletic group originating 9 million years ago (Ma) and that Serrasalmus splits into three distinct clades, all distributed throughout the Amazon, Orinoco and Paraná watersheds (Hubert et al., in press). The biogeography of the Amazon freshwater fish fauna has been largely influenced by the Miocene marine incursion 
that happened at $5 \mathrm{Ma}$ (Hubert \& Renno, 2006; Nores, 1999). The analysis of mtDNA sequences within the Piranha evidenced that the colonisation of the Upper Amazon by the genera Serrasalmus and Pygocentrus occurred after the marine retreat, during the last 4 million years, from the Miocene freshwater refuges of the Brazilian and Guyana shields (Hubert \& Renno, 2006; Hubert et al., in press).

The Madeira is one of the major Andean tributary of the Amazon and previous phylogeographic studies evidenced that the piranha genera Serrasalmus and Pygocentrus colonised the Andean tributaries of the Amazon during only the last $2 \mathrm{Ma}$ (Hubert et al., in press). Although the colonisation of the Upper Madeira is recent, molecular phylogenetic results suggested that speciation occurred in Serrasalmus within the Upper Madeira watershed (Hubert et al., 2006). This may be related to the existence of varied water types in the area as a function of the relative contribution of the Brazilian shield, the Tertiary sediments of the lowlands and the Andes (Sioli, 1975; Guyot et al., 1999). A total of seven Serrasalmus species genetically well differentiated and characterised by private alleles at diagnostic and semi-diagnostic nuclear loci may be found in the area (Hubert et al., 2006). Among this set of well-recognised species, three endemic species from the Madeira River, namely S. compressus, S. hollandi and a Serrasalmus sp (Hubert et al., 2006), constitute a monophyletic group suggesting that speciation occurred within the same watershed (Hubert et $a l .$, in press). If the three species have a recent and common origin, then they may still exhibit shared ancestral polymorphism due to a recent divergence and currently fall within the range of the lineage sorting period. In this context, poor concordance between the gene tree and species tree may be expected. Such a pattern would reinforce the hypothesis of a common geographic origin within the Madeira watershed. Hence, in order to achieve a better understanding of the structuring events and evolution of this endemic group of Serrasalmus 
species in the Upper Madeira River, we explored the genealogy of the mtDNA control region from samples of the three species throughout their distribution range.

\section{Materials and methods}

\subsection{Hydrological context and sampling}

The Madeira River is the second largest tributary of the Amazon $\left(1.37 \times 10^{6} \mathrm{~km}^{2}\right)$ after the Solimões $\left(2.24 \times 10^{6} \mathrm{~km}^{2}\right)$ and is characterised by a marked annual cycle of rainy and dry seasons responsible for multi-peaked floods in the Andean tributaries. The downstream pulse is stored in the Bolivian floodplain, which is one of the largest of the Amazon with a potential flood extension of $0.15 \times 10^{6} \mathrm{~km}^{2}$ (Guyot et al., 1999). The headwaters represent at least $60 \%$ of the overall watershed area and they can be separated into four major systems with distinct hydrological typology (Fig. 1). Currently, three types of water are recognised in the Amazon: (1) the white waters characterised by a great amount of dissolved solid materials and a low transparency (Andean origin); (2) the clear water characterised by a low content of dissolved solid and a high transparency (Brazilian or Guyana shields) and (3) the black water originating from the forested lowlands and differing from the latter by having a higher content of humic acids and a lower $\mathrm{pH}$ (Sioli, 1975). Within the Upper Madeira, the Guaporé River drains almost exclusively the Brazilian shield and so it is characterised by clear waters. By contrast, the Mamoré and Madre de Dios Rivers originate in the Andes. Their main channels are constituted by white waters and small lowland tributaries with black water are frequently encountered along their main channel. Finally, the Yata is a small central tributary hosting black lowland waters.

A total of six rivers were sampled between September 2002 and June 2003 (Fig. 1; Table 1). In the Guaporé, specimens from clear water sites in the headwater (Fig. 1;1) and the lower course (Fig. 1;2) were sampled. In the Mamoré, specimens from one white water 
tributary originating in the Andean flank were sampled (Fig. 1;3) while both a white water (Fig.1; 4) and clear water tributary (Fig. 1; 5) were prospected in the Madre de Dios. A single black water site was sampled from the Yata River (Fig. 1; 6).

\subsection{DNA extraction and sequencing}

Genomic DNA was isolated from ethanol-preserved tissues with the DNeasy Tissue Kit (Qiagen). The mtDNA control region was amplified using the primers CR22U: 5' TGgtTtagtacAtATtATGCAT (Hubert et al., in press) and F-12R: 5' GTCAGGACCATGCCTTTGTG (Sivasundar et al., 2001). These primers amplify a fragment of 980 bp beginning in the position 100 of Colossoma macropomum control region (accession number: AF283963) and including the 3' flanking tRNA genes (tRNA Thr and tRNA Pro). PCR were performed in $50 \mu$ volumes including $13.5-\mu 1$ of template DNA (approximately 1 $\mu \mathrm{g}), 3$ units of Taq DNA polymerase, $5 \mu \mathrm{l}$ of Taq $10 \mathrm{x}$ buffer, $3 \mu \mathrm{l}$ of $\mathrm{MgCl}_{2}(25 \mathrm{mM}), 4 \mu \mathrm{l}$ of $\mathrm{dNTP}(5 \mathrm{mM})$ and $3 \mu \mathrm{l}$ of each primer $(10 \mu \mathrm{M})$. PCR conditions were as follows: $94{ }^{\circ} \mathrm{C}(5$ min), 10 cycles of $94{ }^{\circ} \mathrm{C}(1 \mathrm{~min}), 66{ }^{\circ} \mathrm{C}$ to $56{ }^{\circ} \mathrm{C}$ decreasing of $1{ }^{\circ} \mathrm{C}$ per cycle $(1 \mathrm{~min} 30 \mathrm{~s}), 72$ ${ }^{\circ} \mathrm{C}(2 \mathrm{~min}), 25$ cycles of $94{ }^{\circ} \mathrm{C}(1 \mathrm{~min}), 56{ }^{\circ} \mathrm{C}(1 \mathrm{~min} 30 \mathrm{~s}), 72{ }^{\circ} \mathrm{C}(2 \mathrm{~min})$, followed by $72{ }^{\circ} \mathrm{C}$ (5 min). PCR products were sequenced in both directions. The consensus sequences have been deposited in GenBank and vouchers have been deposited in the Muséum National d'Histoire Naturelle, Paris (Table 1).

\subsection{Analysis of mtDNA variability}

Multiple alignments of the control region were performed using CLUSTAL W (Thompson et $a l .$, 1993). Sequences were aligned with 3 different schemes of gap opening and extending costs as follow, opening cost $=5$ and extending cost $=4$; opening cost $=15$ and extending cost $=6$ (default setting); opening cost $=20$ and extending cost $=8$, in order to detect 
100 potential alignment ambiguous sites defined as positions with gap assignment differing among alternatives cost functions (Gatesy et al., 1994). Phylogenetic relationships among the control region haplotypes sampled were constructed using Maximum Likelihood (ML) as implemented in PhyML (http://atgc.lirmm.fr/phyml) following the algorithm developed by

104 Guindon \& Gascuel (2003). The Akaike Information Criterion (AIC) identified the optimal 105 model as implemented in Modeltest 3.7 (Posada \& Crandall, 1998), and was further used for 106 tree searches and bootstrap analyses based on 1000 replicates in PhyML. Within each mtDNA clades identified, genealogies of the control region haplotypes were constructed following the statistical parsimony method of Templeton et al. (1992) as implemented in the TCS software (Clement et al., 2000). Alternative ambiguous connections resulting from homoplastic 110 mutations were resolved by comparison with the ML tree. Finally, the analysis of molecular 111 variance (AMOVA; Excoffier et al., 1992) provided an estimate of the distribution of 112 nucleotide diversity at three levels of subdivision: among species (CT); among watersheds, 113 within species (SC) and among individuals, within watersheds (ST). The correlation of alleles 114 at each of the three hierarchical levels was assessed using the $\Phi$-statistics (Excoffier et al., 115 1992) tested by 1000 permutations of individuals as implemented in Arlequin 2.0 (Schneider 116 et al., 2000).

\section{Results and discussion}

119 A total of 957 bp were sequenced in 70 specimens including 23 S. compressus, 22 S. hollandi

120 and $25 S$. sp (Table 1). Together with nine sequences of $S$. compressus, $S$. hollandi and $S$. sp 121 previously published (Hubert et al., in press), control region sequences from 79 individuals were analysed here. Serrasalmus marginatus is the sister species of the clade including $S$. compressus, S. hollandi and $S$. sp (Hubert et al., in press) and two sequences of $S$. marginatus

124 previously published were used as outgroup for subsequent analyses (Table 1). 
The three alignments schemes provided the same alignment indicating that no

126 alignment ambiguous sites were present in this data set. Within the 957 sites analysed, 89

127 sites were variable among which 66 were informative, and a single insertion-deletion of $1 \mathrm{bp}$

128 was observed. The AIC indicated that the $\mathrm{HKY}+\mathrm{I}+\Gamma$ model fitted the present data set better

129 than others and was used for subsequent ML searches (Fig. 2; $-\ln L=2239.58$ ). A poor

130 correspondence between the gene tree and the species tree was observed and three clusters of 131 sequences were identified in the ML tree, namely cluster I, II and III (Fig. 2). In general,

132 internal branches were short and deep nodes were statistically poorly supported (Fig. 2). As

133 no alignment ambiguous sites were detected, the lack of statistical support seems to be better

134 explained by a fast differentiation of the mtDNA lineages rather than character conflict due to

135 molecular saturation and homoplasy. The latter hypothesis is consistent with previous

136 phylogenetic results arguing for a fast differentiation of the Serrasalmus lineages (Hubert et 137 al., in press).

138 Cluster I is further subdivided into two distinct clades, the first represented only by

139 sequences from individuals of $S$. compressus and the second by sequences from individuals of

$140 S$. sp (Fig. 2). Likewise, cluster II is further subdivided into two distinct clades, the first

141 including seven sequences from $S$. compressus and the second including 18 sequences from $S$.

$142 \mathrm{sp}$ in addition to one from $S$. compressus. The parsimony network inferred for cluster II

143 indicates that haplotype sharing occurs between these two species and hybridisation and

144 introgression cannot be rejected. Finally, cluster III harbours no subdivision. This clade

145 consists of a poorly supported polytomy represented by sequences from both $S$. hollandi and

$146 S$. sp. Once again, the parsimony network evidences some haplotype sharing between these

147 two species, which cannot be explained by the retention of ancestral polymorphism alone. In

148 this case, introgression through hybridisation is likely. The AMOVA evidenced that most of

149 the nucleotide variability was found within watershed rather than species as $50 \%$ of the 
variability in the control region sequences was explained by variation within watershed while only $33 \%$ of the variability was explained by differences between species (Table 2). However, the variation between species was found significant indicating that drift shaped species genealogy for long enough to imprint a significant differentiation of the mtDNA lineages.

The maintenance of ancestral polymorphism from a common ancestor may be expected to result in a distinct distribution of the coalescent events between species when compared with hybridisation and gene flow. Recent isolation and ancient polymorphism is likely to relate species through coalescent events generally older than the speciation event as homogamy tend to increase the proportion of young coalescent events within species (Pamilo \& Nei, 1988). By contrast, hybridisation and gene flow will relate species polymorphism through coalescent events from varied ages (Wakeley, 1996). In this context, distributions of pairwise differences between species are likely to be distinct when considering isolation and ancestral polymorphism or gene flow through hybridisation, the latter leading to haplotype sharing of recently derived haplotypes and young coalescent events between species.

Distribution of pairwise differences within species and within clusters confirmed that the clusters poorly matched the species limits as sequences were more closely related within clusters than within species (Fig. 2). Likewise, the distribution of pairwise differences between species exhibited a complex trimodal distribution very similar to the distribution of pairwise differences within species. A major mode is found around 15-17 differences and two minor modes, the first around two differences and the second around 33-35 differences (Fig. 2D). The superposition of the modes around 15-17 and 33-35 differences in the within species and between species distributions is characteristic of recent isolation and ancient polymorphism with an excess of old coalescent events within species. By contrast, the mode around 2 differences between species is characteristic of young coalescent events within species rather than between species (Fig. 2D). If introgression through past hybridisation 
175 created this mode between sympatric species, comparisons with an allopatric and physically

176 isolated outgroup should differ by lacking it. The distribution of pairwise differences between

$177 S$. marginatus from the Paraná and $S$. compressus, $S$. hollandi and $S$. sp from the Madeira

178 lacks this mode at two differences and further supports that the excess of recent coalescent

179 events between sympatric species from the Madeira originated from introgression through 180 past hybridisation (Fig. 2E).

181 The present pattern of mixed mtDNA lineages between species has several 182 implications. The distributions of pairwise differences between sympatric ( $S$. compressus, $S$.

183 hollandi, S. sp) or allopatric species (with S. marginatus) indicate that recent isolation and 184 ancestral polymorphism alone is unlikely to produce haplotype sharing and account for the 185 occurrence of recent coalescent events between sympatric species. The present result makes 186 the hypothesis of mtDNA introgression through past hybridisation very likely. This contrast 187 with the well differentiation of allelic pools from nuclear DNA (nDNA) previously described 188 between Serrasalmus compressus, S. hollandi and S. sp (Hubert et al., 2006). Actually, 189 several causes may be account to this apparent discrepancy between mtDNA and nDNA. 190 Only size differences between alleles were previously assessed for nDNA and pattern of 191 coalescence between alleles has not been considered (Hubert et al., 2006). Hence, recent 192 coalescent events between species in the nDNA may have not been previously detected 193 through the analyses of length differences due to insertion-deletion events. However, this 194 artefact seems unlikely in front of the number of nuclear loci previously analysed (Hubert $e t$ 195 al., 2006) Alternatively, the occurrence of mtDNA introgression through maternal lineages 196 cannot be discarded and seems very likely.

197 Another implication from the present study concerns the geography and ecology of the 198 speciation events at the origin of the three sympatric species from the Upper Madeira, namely 199 S. compressus, S. hollandi and S. sp. The genealogy of the control region haplotypes argues 
that this group of sympatric species still falls in the range of the lineage sorting period. The

201 three species are tightly restricted to the Madeira River and the present pattern supports a common and recent origin in the same watershed rather than more complex scenarios involving allopatric divergence in different watersheds, secondary contacts and extirpations. Also, the abundance of each of the three species in the different tributaries of the Upper

Madeira was not properly addressed here, as this was not the focus of the present study, some trends seems to emerge from the present sampling (Table 1). The two species, Serrasalmus hollandi and $S$. sp seems to be alternatively distributed as the former was more frequently sampled in white- to mixed-water tributaries (Béni and Mamoré river) while the latter was almost exclusively observed in clear- to black-water tributaries (Yata, Itenez and Manuripi 210 rivers). Cytogenetic studies of Serrasalmus in the central Amazon previously detected cryptic 211 reproductive units distributed alternatively in white or black waters (Centofante et al., 2002).

212 The present pattern supports a recent and common geographic origin and suggests that 213 adaptive divergence to the variety of water type in the headwaters of the Madeira River may 214 have been an important factor in shaping reproductive isolation between these endemic 215 species (Schluter, 2001).

\section{Acknowledgments}

218 This work was part of the $\mathrm{PhD}$ of Nicolas Hubert on the evolution of the piranha. This 219 research was supported by Institut de Recherche pour le Développement (IRD, France); 220 Instituto de Biología Molecular y Biotechnología, La Paz (IBM y B, Bolivia), Instituto de 221 Limnología, La Paz (Bolivia), and the laboratory GPIA, Montpellier (France). We thank N. 222 Bierne, B. Guinand and E. Lambert from the GPIA laboratory; G. Rodriguo, N. Mamani and 223 V. Iñiguez from the IBMB for laboratory supports and facilities. We wish to thank F. 224 Carvajal, A. Parada, L. Torres, T. Yunoki for their help during field sampling, J. Pinto, R. 
Marin and M. Legendre for their support. We thank P. Pruvost, L. Nandrin and R. Causse 226 from the MNHN for providing facilities in the ichthyological collection.

\section{References}

Bowie, R.C., Fjeldså, J., Hackett, S.J., Bates, J.M., Crowe, T.M., 2005. Coalescent models reveal the relative roles of ancestral polymorphism, vicariance, and dispersal in shaping phylogeographical structure of an African montane forest robin. Molecular Phylogenetics and Evolution 38, 171-188.

Buckup, P.A., 1998. Relationships of the Characidiinae and phylogeny of Characiform fishes (Teleostei: Ostariophysi). In: Malabarba, L.R., Reis, R.E., Vari, R.P., Lucena, Z.M., Lucena, C.A.S. (Eds.), Phylogeny and classification of Neotropical fishes, Universidade Católica do Rio Grande do Sul, Porto Alegre (EDIPUCRS), pp. 251-260.

Centofante, L., Porto, J.I.R., Feldberg, E., 2002. Chromosomal polymorphism in Serrasalmus spilopleura Kner, 1858 (Characidae, Serrasalminae) from central Amazon Basin. Caryologia 55, 37-45.

Chiang, T.Y., 2000. Lineage sorting accounting for dissociation between chloroplast and mitochondrial lineages in oaks of southern france. Genome 43, 1090-1094.

242 Clement, M., Posada, D., Crandall, K.A., 2000. TCS: a computer program to estimate gene genealogies. Molecular Ecology 9, 1657-1659.

244 Excoffier, L., Smouse, P., Quattro, J.M., 1992. Analysis of molecular variance inferred from metric distances among DNA haplotypes: an application to human mitochondrial DNA

247 Funk, D.J., Omland, K.E., 2003. Species-level paraphylyl and polyphyly: frequency, causes 248 and consequences, with insights from animal mitochondria DNA. Annula Review of 249 Ecology, Evolution and Systematics 34, 397-423. 
Gatesy, J., DeSalle, R., Wheeler, W., 1994. Alignment ambiguous nucleotide sites and the exclusion of systematic data. Molecular Phylogenetics and Evolution 2, 152-157.

252 Guindon, S., Gascuel, O., 2003. A simple, fast, and accurate algorithm to estimate large phylogenies by Maximum Likelihood. Systematic Biology 52, 696-704.

Guyot, J.L., Jouanneau, J.M., Wasson, J.G., 1999. Characterisation of the river bed and suspended sediments in the Rio Madeira drainage basin (Bolivian Amazonia). Journal of South American Sciences 12, 401-410.

Hoelzer, G.A., Wallman, J., Melnick, D.J., 1998. The effects of social structure, geographical structure, and population size on the evolution of mitochondrial DNA: II. Molecular clocks and the lineage sorting period. Journal of Molecular Evolution 47, 21-31.

Hubert, N., Duponchelle, F., Nuñez, J., Riveira, R., Renno, J.F., 2006. Evidence of reproductive isolation among sympatric closely related species of Serrasalmus (Ostariophysii, Characidae) from the Upper Madeira River. Journal of Fish Biology 69A, $31-51$.

Hubert, N., Renno, J.F., 2006. Historical Biogeography of South American Freshwater fishes. Journal of Biogeography 33, 1414-1436.

Hubert, N., Duponchelle, F., Nuñez, J., Garcia-Davila, C., Paugy, D., Renno, J.F. (in press) Phylogeography of the piranha genera Serrasalmus and Pygocentrus: implications for the diversification of the Neotropical Ichthyofauna. Molecular Ecology.

Jégu, M., 2003. Serrasalminae. In: Reis, R.E., Kullander, S.O., Ferraris, C.J. (Eds.), Check List of freshwater fishes of South and Central America. Universidade Católica do Rio Grande do Sul, Porto Alegre (EDIPUCRS), pp. 182-196.

Kingman, J.F.C., 1982. The coalescent. Stochastic Process and their Applications 13, 245248. 
274 Machado, C.A., Hey, J., 2002. The causes of phylogenetic conflict in a classic Drosophila 275 species group. Proceedings of the Royal Scoiety of London, Series B 270, 1193-1202.

276 Nielsen, R., Wakely, J.,2001. Distinguishing migration from isolation: a markov chain monte 277 carlo approach. Genetics $158,885-896$.

278 Nores, M., 1999. An alternative hypothesis to the origin of Amazonian bird diversity. Journal 279 of Biogeography 26, 475-485.

280 Pamilo, P., Nei, M., 1988. Relationships between gene trees and species trees. Molecular $281 \quad$ Biology and Evolution 5, 568-581.

282 Posada, D., Crandall, K.A., 1998. Modeltest: testing the model of DNA substitution. 283 Bioinformatics 14, 817-818.

284 Rokas, A., Melika, G., Abe, Y., Nieves-Aldrey, J.L., Cook, J.M., Stone, G.N., 2003. Lifecycle 285 closure, lineage sorting, and hybridization revealed in a phylogenetic analysis of european 286 oak gall wapsps (Hymenoptera: Cynipidae: Cynipini) using mitochondrial sequence data. 287 Molecular Phylogenetics and Evolution 26, 36-45.

288 Rosenberg, N.A., 2003. The shapes of neutral gene genealogies in two species: probabilities 289 of monophyly, paraphyly, and polyphyly in a coalescent model. Evolution 57, 1465-1477. 290 Schluter, D., 2001. Ecology and the origin of species. Trends in Ecology and Evolution 16, $291 \quad 372-380$.

292 Schneider, S., Roessli, D., Excoffier, L., 2000. Arlequin version 2.0: a software for population 293 genetic data analysis. Genetics and Biometry Laboratory, University of Geneva. Geneva, 294 Switzerland.

295 Sioli, H., 1975. Tropical rivers as expressions of their terrestrial environments. In: Golley, 296 F.B., Medina, E. (Eds.), Tropical Ecological Systems: Trends in Terrestrial and Aquatic 297 Research, Springer Verlag, Berlin, pp. 275-288. 
298 Sivasundar, A., Bermingham, E., Ortí, G., 2001. Population structure and biogeography of 299 migratory freshwater fishes (Prochilodus: Characiformes) in major South American rivers. $300 \quad$ Molecular Ecology 10, 407-417.

301 Tajima, F., 1983. Evolutionary relationships of DNA sequences in finite populations. 302 Genetics 105, 437-460.

303 Takahashi, K., Terai, Y., Nishida, M., Okada, N., 2001. Phylogenetic relationships and 304 ancient incomplete lineage sortin among cichlid fishes in lake tanganyika as revealed by 305 analysis of the insertion of retroposons. Molecular Biology and Evolution 18, 2057-2066.

306 Templeton, A.R., Crandall, K., Sing, C.F., 1992. A cladistic analyses of phenotypic 307 associations with haplotypes inferred from restriction endonuclease mapping and DNA 308 sequence data. III. Cladogram estimation. Genetics 132, 619-633.

309 Thompson, J.D., Higgins, D.G., Gibson, T.J., 1993. CLUSTAL W: improving the sensitivity 310 of progressive multiple sequence alignment through sequence weighting, position-specific 311 gap penalties and weight matrix choice. Nucleic Acids Research 22, 4673-4680.

312 Wakeley, J., 1996. The variance of pairwise nucleotide differences in two populations with 313 migration. Theoritical Populations Biology 49, 39-57. 
314 Fig. 1. Distribution range of Serrasalmus marginatus, S. compressus, S. hollandi and known

315 sampling area of $S$. sp, and sampling sites of $S$. compressus, $S$. hollandi and $S$. sp within the

316 Upper Madeira watershed (each point may represent more than one locality). The Brazilian

317 shield is represented in light grey while the Andes are represented in dark grey. 1, upper

318 Guaporé; 2, lower Guaporé in the San Martin River; 3, lower Mamoré in the Isiboro River; 4,

319 Béni River in the Madré de Dios watershed; 5, Orthon River in the Manuripi tributary; 6, Yata

320 River.

322 Fig. 2. Phylogenetic relationships among control regions sequences of Serrasalmus

323 compressus, $S$. hollandi and $S$. sp. A. ML tree inferred using the model $\mathrm{HKY}+\mathrm{I}+\Gamma$ with the

324 following parameters: base frequencies $\mathrm{A}=0.31, \mathrm{G}=0.22, \mathrm{C}=0.17, \mathrm{~T}=0.30$,

325 transition/transversion ratio $=11.98$, proportion of invariable sites $=0.76$, gamma shape

326 parameter $=0.66$, number of categories $=4$. For each cluster identified, the corresponding

327 genealogy inferred using the statistical parsimony framework of Templeton et al., 1992 is

328 provided. Ancestral haplotypes inferred are indicated with bold lines. B, mismatch

329 distribution of pairwise differences within the three species $S$. compressus, S. hollandi and $S$.

330 sp. C, mismatch distribution of pairwise differences within the three clusters I, II and III. D,

331 mismatch distribution of pairwise differences between species within the clade including

332 cluster I, II and III. E, mismatch distribution of pairwise differences between the outgroup and

333 the species from the clade including cluster I, II and III. 


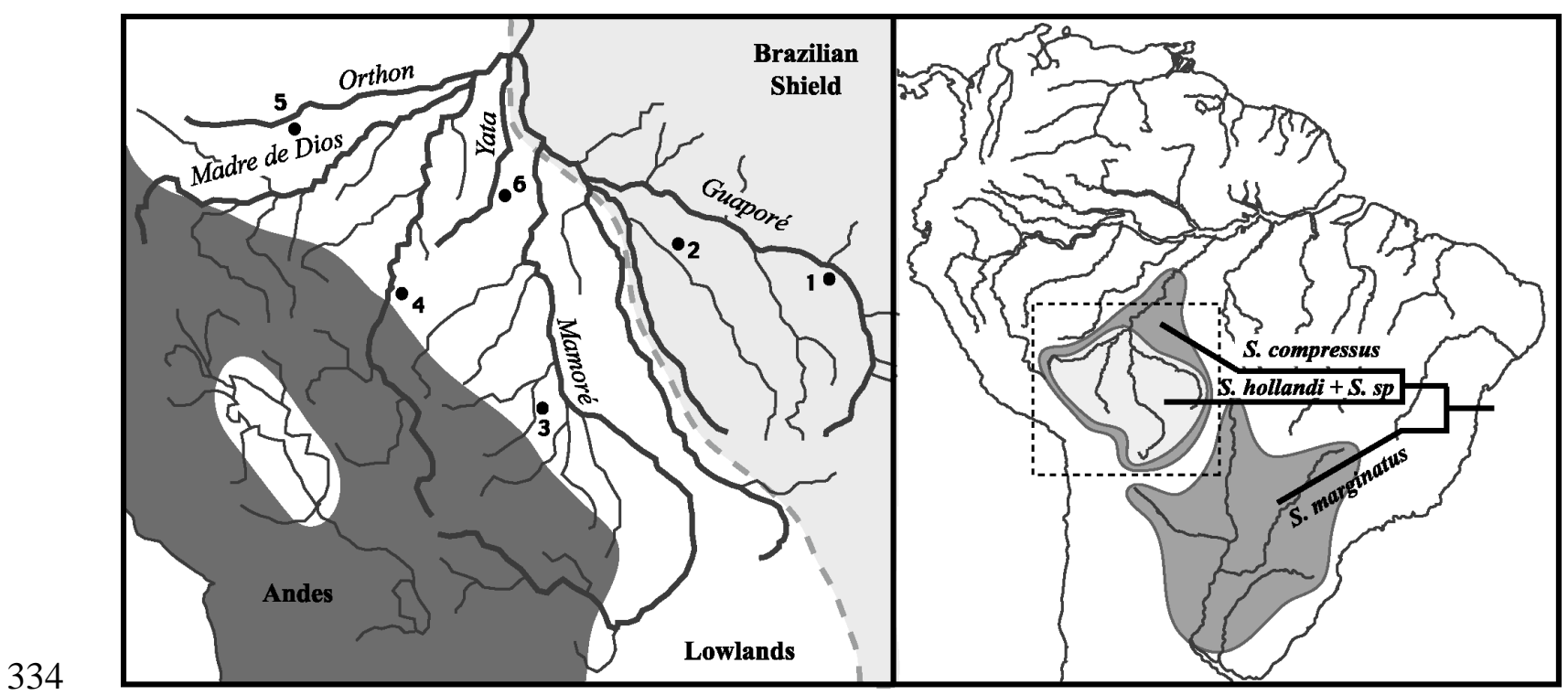



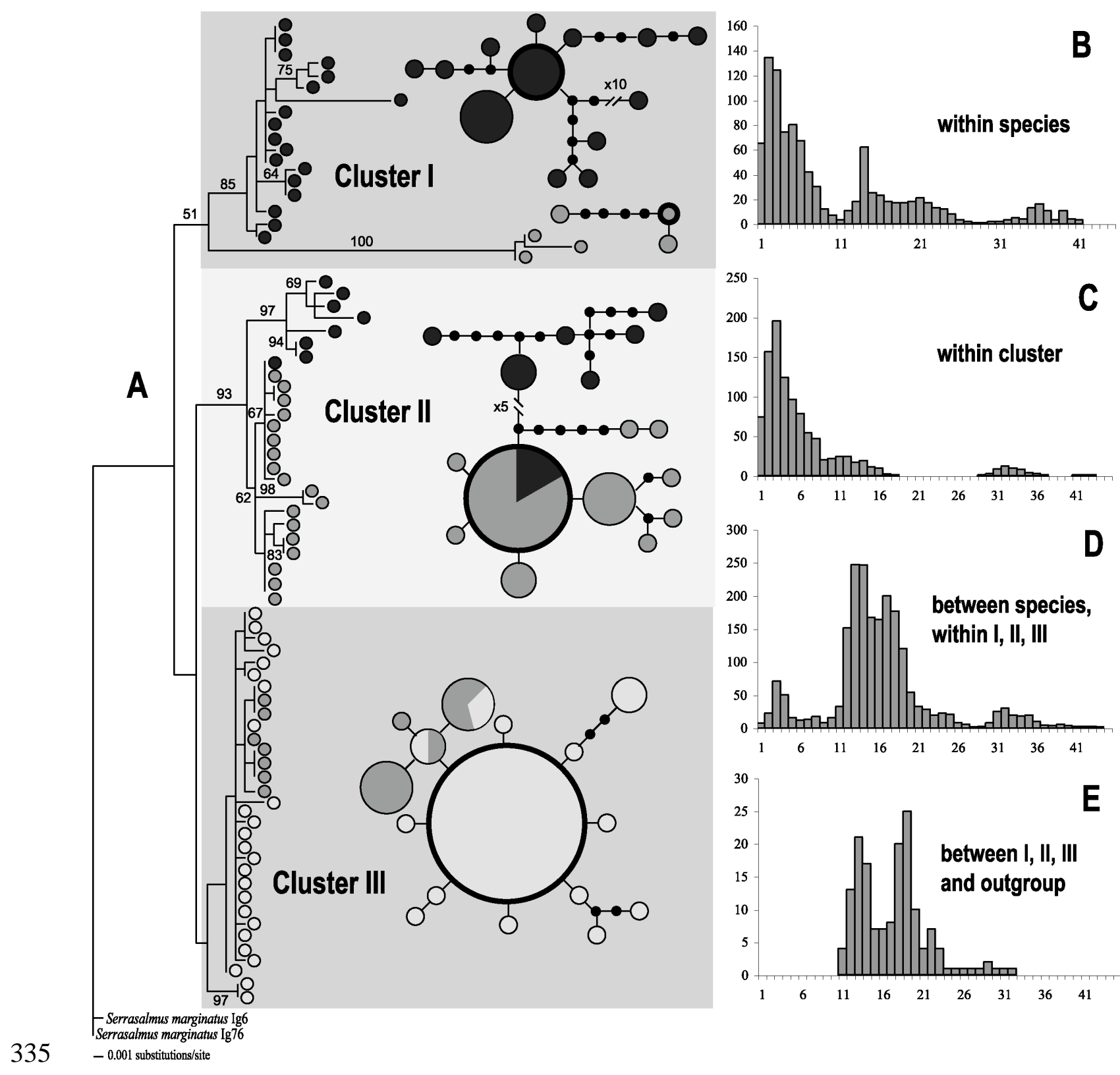

within cluster
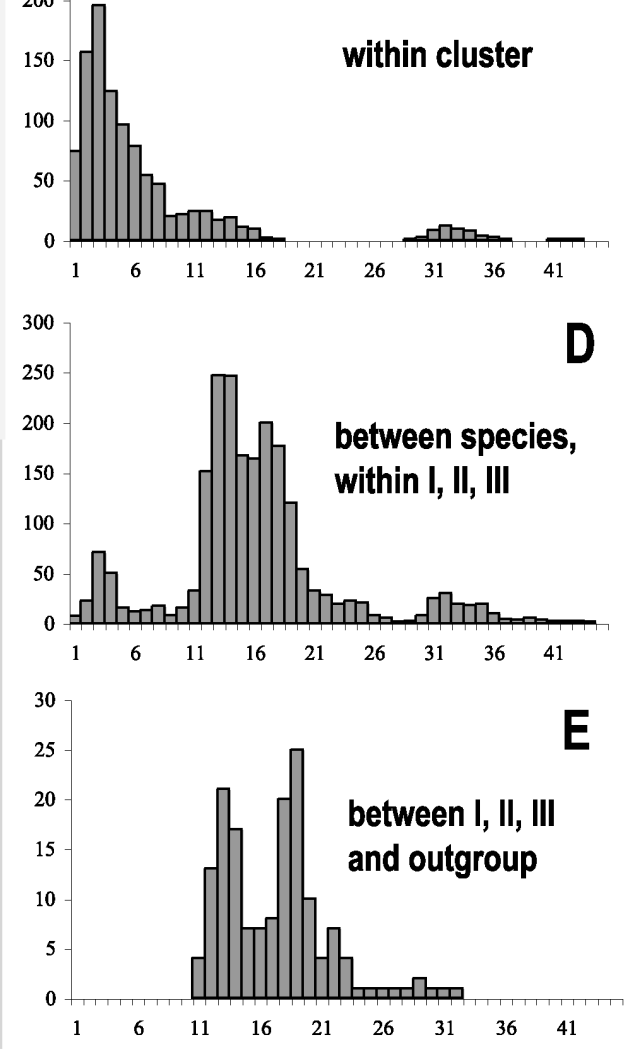